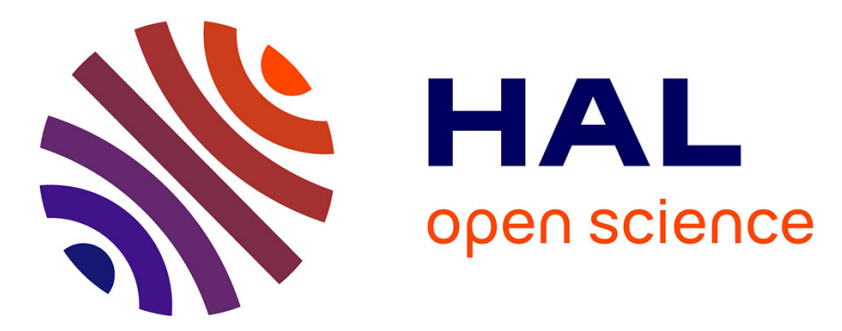

\title{
Enantioselective separation under humid conditions by chiral Hofmann clathrates: new opportunities for vintage materials
}

Ekaterina Mamontova, Philippe Trens, Fabrice Salles, Bernard Fraisse, Olinda Carreon Gimello, Yannick Guari, Joulia Larionova, Jérôme Long

\section{To cite this version:}

Ekaterina Mamontova, Philippe Trens, Fabrice Salles, Bernard Fraisse, Olinda Carreon Gimello, et al.. Enantioselective separation under humid conditions by chiral Hofmann clathrates: new opportunities for vintage materials. Inorganic Chemistry Frontiers, 2019, 6, pp.3245-3254. 10.1039/c9qi00837c . hal-02348403

\section{HAL Id: hal-02348403 \\ https://hal.science/hal-02348403}

Submitted on 18 Nov 2020

HAL is a multi-disciplinary open access archive for the deposit and dissemination of scientific research documents, whether they are published or not. The documents may come from teaching and research institutions in France or abroad, or from public or private research centers.
L'archive ouverte pluridisciplinaire HAL, est destinée au dépôt et à la diffusion de documents scientifiques de niveau recherche, publiés ou non, émanant des établissements d'enseignement et de recherche français ou étrangers, des laboratoires publics ou privés. 


\section{Enantioselective separation in humid conditions by chiral Hofmann Clathrates: new opportunities for vintage materials}

Ekaterina Mamontova, ${ }^{\mathrm{a}}$ Philippe Trens*, ${ }^{\mathrm{b}}$ Fabrice Salles, ${ }^{\mathrm{c}}$ Bernard Fraisse, ${ }^{\mathrm{c}}$ Olinda Gimello, ${ }^{\mathrm{b}}$ Yannick Guari, ${ }^{\mathrm{a}}$ Joulia Larionova ${ }^{\mathrm{a}}$ and Jérôme Long*a

Chiral separation is of critical importance in many areas spanning from pharmaceutics and agriculture to catalysis. Coordination polymers and Metal-Organic Frameworks have been envisaged for such purpose. In this study, the post-synthetic functionalization of the two-dimensional Hofmann clathrate $\left[\mathrm{Ni}\left(\mathrm{H}_{2} \mathrm{O}\right)_{2}\right]\left[\mathrm{Ni}(\mathrm{CN})_{4}\right]$ by enantiopure phenylethylamines yielding hydrostable chiral clathrates is reported. In the case of $(R)$ and $(S)$ butan-2-ol, we demonstrate that the obtained coordination frameworks exhibit clear enantioselective properties, which can be used for the separation of enantiomers in humid conditions.

\section{Introduction}

Chirality is a matter of critical importance in many areas such as biology, ${ }^{1}$ pharmaceutical industry, ${ }^{2}$ agriculture ${ }^{3}$ and catalysis. ${ }^{4}$ Several molecules emblematic of life on Earth, such as amino acids or carbohydrates, exist in both, right and left handed shape. However, biological life has a marked preference for only one enantiomer (phenomenon called a homochirality), which cannot be superposed on its mirror image. ${ }^{5}$ Moreover, most part of biological processes involving metabolites and enzymes usually show a high degree of specificity toward only one enantiomer. ${ }^{6}$ Right and left handed enantiomers can exhibit large differences in their behavior in the living organisms in terms of recognition by receptors, physiological activity, absorption, distribution and clearance, potency, metabolism and toxicology. In this sense, a large percentage of pharmaceutical agents and drugs are optically active and therefore specifically interact through chiral recognition. ${ }^{7-9}$ Following the Food and Drug Administration (FDA) statement, while some drug enantiomers present similar pharmacological effect, such as ibuprofen, others might have completely antagonist harmful activities. ${ }^{6}$ Hence, the separation of enantiomers is decisive for both, economic and health concerns..$^{7-10}$

Regardless the targeted application, chiral recognition is a necessary condition to ensure the efficiency of the enantiomers' separation. In the industry, various processes allowing the separation of enantiomers using chiral stationary phases have been developed starting from a procedure applied in early 1970's involving the immobilization of optically active small molecules on silica gels or organic polymers. ${ }^{11}$ This method is still widely used in separation chromatography but the rather recent developments made this functionalization of lesser interest. ${ }^{12-13}$ Amongst these, bio-sourced, synthetic imprinted or helical polymers proved to be successful, even though their synthesis was not straightforward. ${ }^{14-15}$ However, the mobile phase is usually difficult to define for a specific bio-polymer and each system therefore requires a long term optimization due to the complexity of the supported functionalities. Furthermore, the specific surface area was not considered as a primary parameter in these materials and, hence, developing the internal surface appears highly important to increase the efficiency of the separation.

In this sense, microporous chiral materials exhibiting a permanent porosity could be therefore viewed as promising systems for enantioselective separation. Nevertheless, the design of mechanically and thermally robust inorganic chiral frameworks, such as zeolites, is highly challenging, although some approaches involving the synthesis with chiral directing or inductive agents have already been proposed. ${ }^{16}$ Moreover, the size and the topology of the zeolite's pores may be difficult to adjust towards specific guests as, for instance, large organic molecules found in the pharmaceutics. Following this idea, chiral and porous molecule-based materials, such as Metal-Organic Frameworks (MOF) are promising for such purpose owing to their flexible molecular structures, adjustable pores' size/shape and chemical affinity towards targeted guest molecule. ${ }^{17-20}$ 


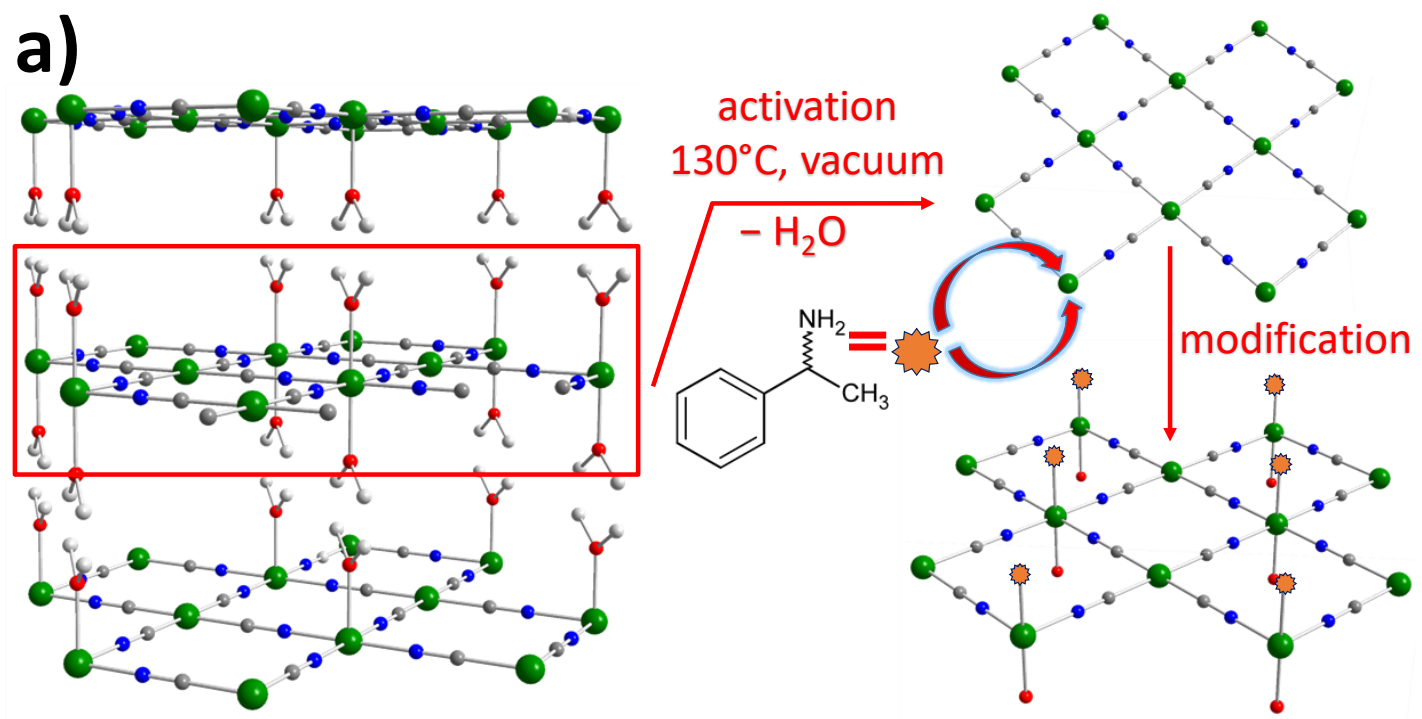

1
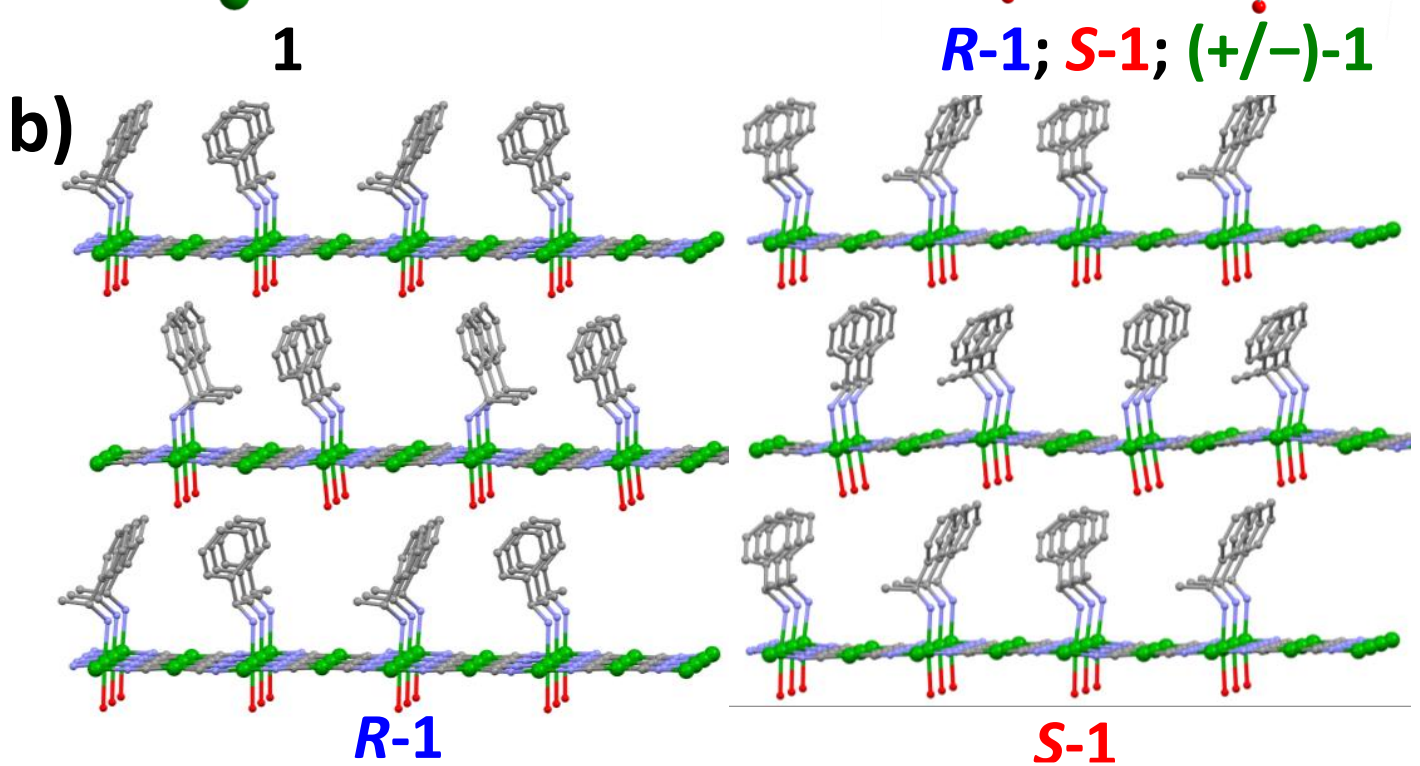

Fig. 1 a) Scheme showing the PSM methodology. Colour code: green, Ni; blue, N; red, O; grey, C; b) Crystal structures of $R$-1 and S-1 obtained by structural optimization Fig. 1 a) Scheme showing the PSM method
(DFT) with an alignment of the ligands.

Different synthetic strategies have been employed to design such chiral MOF consisting in the spontaneous resolution starting from achiral precursors, ${ }^{21-22}$ use of chiral templating or induction by chiral agents ${ }^{7,23-24}$ and direct synthesis with enantiopure building blocks. ${ }^{4,25-26}$ While the two former strategies may suffer from predictability due to hardly controllable factors, the latest one often requires expensive or complex building blocks that may limit the synthesis at the multigram scale. Another appealing approach consists in the post-synthetic modification (PSM) of achiral architectures using a large variety of enantiopure molecules that, in addition, allows the specific tailoring of the chemical affinity for a targeted application. ${ }^{23,27-28}$ Furthermore, the easiness of the synthesis, as well as the low cost of some enantiopure molecules constitute an interesting asset. Yet, this strategy requires the presence of reactive or coordinatively unsaturated sites (CUS) in order to ensure a strong chemical interaction between the framework and the grafted chiral species.

On the other hand, the aforementioned targeted applications frequently necessitate performing such enantioselective separation in the presence of water at different stages, which could be of critical importance for the separation of some hydrosoluble racemic compounds, such as drugs. This therefore requires the use of materials with a strong robustness towards water, liquid or as vapor. Additionally, liquid separations could be performed above room temperature, which addresses also the hydrothermal stability of these materials. Considerable efforts have recently been made in the family of chiral MOFs in this connection and several examples of hydrostable chiral MOFs have recently been reported, ${ }^{29-32}$ but such systems remain scarce. Moreover and to our knowledge, the investigations on the enantioselective separation in humid conditions have never been achieved using chiral MOF.

In this line of thought, Hofmann Clathrates represent a promising alternative to MOF because they present all the aforementioned advantages of MOFs, while exhibiting an exceptional hydrothermal stability. ${ }^{33}$ These extended architectures consist in octahedral transition metals ions $\mathrm{M}^{\prime 2+}$ connected through cyano-bridges, provided by square-planar tetracyanometallate complexes $\left[\mathrm{M}(\mathrm{CN})_{4}\right]^{2-}$, generating grid-like layers assembled in 2D structure. The octahedral $\mathrm{M}^{\prime 2+}$ ions complete their coordination sphere 
with two trans ligands, which can be substituted to functionalize the coordination network. For instance, a vast variety of bidenta te bridging ligands has been used to obtain 3D-pillared Hofmann clathrates for spin-crossover ${ }^{34-38}$ or gas adsorption studies. ${ }^{39-41}$ In this article, we report an elegant strategy to design new chiral Hoffmann Clathrates by the post-synthetic functionalization of a two-dimensional cyano-bridged compound $\left[\mathrm{Ni}\left(\mathrm{H}_{2} \mathrm{O}\right)_{2}\right]\left[\mathrm{Ni}(\mathrm{CN})_{4}\right] \cdot 1.5 \mathrm{H}_{2} \mathrm{O}$ by a simple and affordable enantiopure $R$ or $S$ phenylethylamine ligands and demonstrate the enantioselective adsorption of butan-2-ol and the separation of its racemic mixture in humid conditions.<smiles>C[C@H](N)c1ccccc1</smiles>

$\boldsymbol{R}$-(+)-phenylethylamine<smiles>C[C@H](N)c1ccccc1</smiles>

$S$-(-)-phenylethylamine

Scheme 1 Schematic representation of ligands $R-(+)$-phenylethylamine and $S-(-)$-phenylethylamine.

\section{Results and Discussions}

\section{Synthesis and characterization}

The PSM to implement chirality relies on the use of a well-known two-dimensional compound $\left[\mathrm{Ni}\left(\mathrm{H}_{2} \mathrm{O}\right)_{2}\right]\left[\mathrm{Ni}(\mathrm{CN})_{4}\right] \cdot 1.5 \mathrm{H}_{2} \mathrm{O}(\mathbf{1})$, which is one of the benchmark Hofmann clathrates (Fig. 1).42-44 The water molecules occupying the axial coordination sites could be easily removed to generate CUS. ${ }^{39-41}$ Thus, activation of 1 under vacuum at $130{ }^{\circ} \mathrm{C}$ followed by the addition of 2 equivalents of either $R$, $S$, or racemic (+/-) phenylethylamine $(L$, Scheme 1$)$ in chloroform affords the formation of light purple solids for $R-\mathbf{1}, S-\mathbf{1}$ and light blue solid for (+/-)-1, respectively (Fig. S1). The amine functions of $L$ ensure their coordination with the octahedral $\mathrm{Ni}^{2+}$ sites. The presence of $L$ in the materials is confirmed by the FT-IR spectra, which exhibit its characteristic bands in the $400-1600 \mathrm{~cm}^{-1}$ spectral window in addition to the cyanide $v\left(\mathrm{Ni}^{\mathrm{ll}} \mathrm{CN}-\mathrm{Ni}{ }^{\prime \prime}\right)$ stretching located at $2166 \mathrm{~cm}^{-1}$ for all functionalized compounds (Fig. S2S3). This latter value is slightly shifted to lower wavenumbers with respect to the pristine compound $1\left(v\left(\mathrm{Ni}^{\prime \prime} \mathrm{CN}-\mathrm{Ni}{ }^{\prime \prime}\right)=2171 \mathrm{~cm}^{-1}\right)$ indicating a weak modification of the electronic density. Elemental and Thermo-Gravimetric Analyses (TGA) (Fig. S4) allow the estimation of the ligand and water content giving the following formula $\left[\mathrm{Ni}(R-L)_{1.40}\left(\mathrm{H}_{2} \mathrm{O}\right)_{0.60}\right]\left[\mathrm{Ni}(\mathrm{CN})_{4}\right] \bullet 0.3 \mathrm{H}_{2} \mathrm{O}(R-1)$, $[\mathrm{Ni}(S-$ $\left.L)_{1.40}\left(\mathrm{H}_{2} \mathrm{O}\right)_{0.60}\right]\left[\mathrm{Ni}(\mathrm{CN})_{4}\right] \bullet 0.3 \mathrm{H}_{2} \mathrm{O}(\mathrm{S}-\mathbf{1})$ and $\left[\mathrm{Ni}((+/-)-L)_{0.94}\left(\mathrm{H}_{2} \mathrm{O}\right)_{1.06}\right]\left[\mathrm{Ni}(\mathrm{CN})_{4}\right] \bullet 1.2 \mathrm{H}_{2} \mathrm{O}((+/-)-\mathbf{1})$. We note that in all cases, it was not possible to achieve a full saturation of the CUS that would correspond to two $L$ moieties per octahedral $\mathrm{Ni}^{2+}$ ions. Besides, a lower ligand content is observed when the reaction is performed with the racemic mixture of $L$, suggesting a different organization of the structures depending on the chirality of the phenylethylamine. TGA analysis (Fig. S4) shows two distinct weight losses below $190^{\circ} \mathrm{C}$, which could be imputed to interstitial and coordinated water molecules, respectively. While 1 is thermally stable up to 350 ${ }^{\circ} \mathrm{C}$, TGA curves of $R-\mathbf{1}, S-1$ and (+/-)-1 show that the phenylethylamine is lost in the temperature range $200-300{ }^{\circ} \mathrm{C}$ for the postfunctionalized clathrates, which remains slightly higher than its boiling point (i.e. $187^{\circ} \mathrm{C}$ ) due to its stabilization through coordination to the metal-cyanide network.

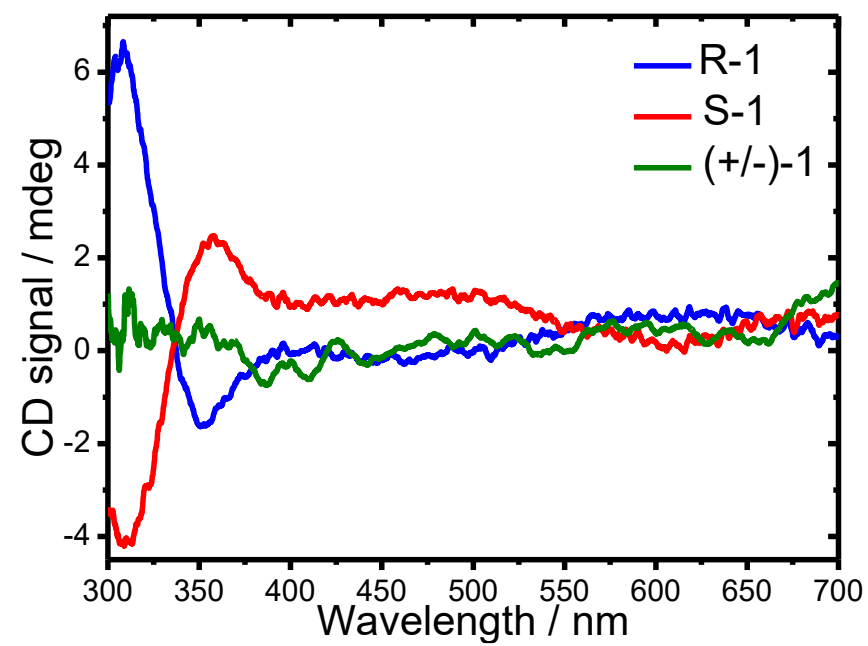

Fig. 2. Solid-state (KBr pellet) CD spectra of $R-\mathbf{1}$ (blue), $S-1$ (red) and (+/-)-1 (green) at room temperature. 
Further evidence for the incorporation of the chiral ligands into the structure could be obtained using solid-state Circular Dichroism (CD) spectroscopy. While the functionalized racemic (+/-)-1 clathrate does not show any optical activity, $R-\mathbf{1}$ and $S-\mathbf{1}$ exhibit mirrorsymmetrical dichroism with Cotton effects of opposite signs at $\lambda_{\max }=310,355$ and $575 \mathrm{~nm}$ confirming their enantiomeric relationship (Fig. 2). The broad band at around $575 \mathrm{~nm}$ could be ascribed to the $d$ - $d$ transitions of the octahedral $\mathrm{Ni}^{2+}$ observed in comparable clathrates, ${ }^{45-46}$ while the bands in the UV domain correspond to charge transfers of the $\left[\mathrm{Ni}(\mathrm{CN})_{4}\right]^{2-}$ and $L$ moieties. These results confirm: (i) the coordination of the chiral ligand to the octahedral $\mathrm{Ni}^{2+}$, and (ii) the observed chirality transfer from $L$ to the host-structure.

Insights into the structural changes generated by the PSM could be obtained by Powder X-Ray Diffraction (XRPD) analysis. The XRPD pattern and the Le Bail refinement for the pristine material 1 are consistent with the previously published phase crystallizing in the orthorhombic Ima2 space group (Fig. 3, Fig. S5, Table S1). ${ }^{42}$ Upon functionalization with L, the pattern was largely changed. While the functionalization with either the enantiopure $R$ or $S$-phenylethylamine generates comparable PXRD patterns, the use of the racemic phenylethylamine yields a different diffractogram (Fig. 3). Le Bail refinements (Fig. S5, Table S1) indicate that $R-1$ and $S-1$ crystallize in the non-centrosymmetric monoclinic space group $P 2$, which is in full agreement with the results obtained from $\mathrm{CD}$. Although, the racemic clathrate (+/-)-1 pattern could be refined either in the $P 2$ or $P 2 / m$ space groups due to identical extinction rules, the absence of dichroic signals rather suggests a crystallization in the centrosymmetric $P 2 / m$ space group (Table S1).

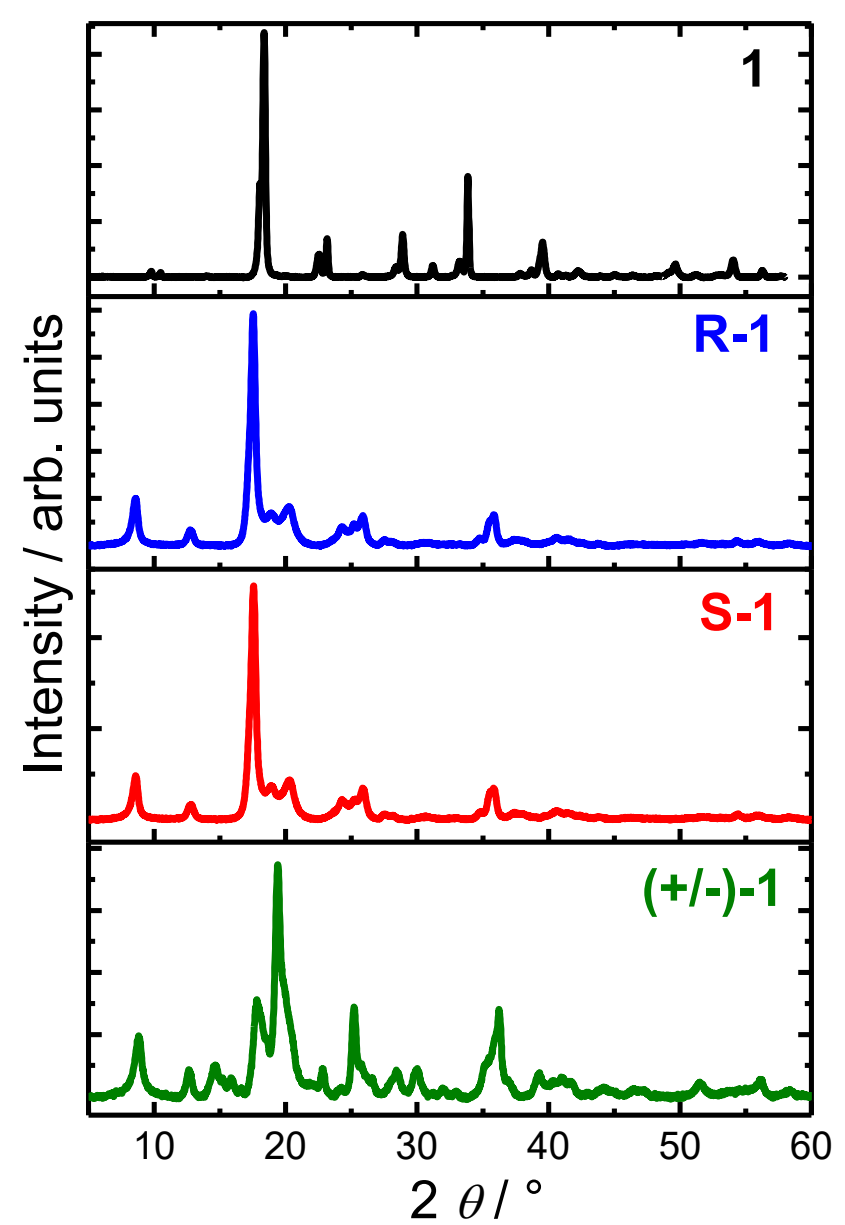

Fig. 3. PXRD patterns of $\mathbf{1}$ (black), $R-\mathbf{1}$ (blue), $S-\mathbf{1}$ (red) and (+/-)-1 (green).

To go further, theoretical modelling was performed in link with PXRD patterns to propose the best models for $R-\mathbf{1}$ and $S-1$. Using DFT calculations, two different organizations of the phenylethylamine ligands have been tested for both $L$ handednesses and the resulting configuration energy was estimated. $2 \mathrm{D}$ structures made by layers of $\left[\mathrm{Ni}(R / \mathrm{S}-L)\left(\mathrm{H}_{2} \mathrm{O}\right)\right]\left[\mathrm{Ni}(\mathrm{CN})_{4}\right]$ were considered, employing a simple model in which each octahedral $\mathrm{Ni}^{2+}$ ion is coordinated by a chiral ligand $L$ and a water molecule located in trans fashion. It turns out that the lowest energy value consists in the regular alignment of the chiral ligands and water molecules (Fig. 1b) in contrast to an alternate sequence (Fig. S6, Table S2). Such fact could be rationalized by the presence of strong intralayers $\pi-\pi$ interactions involving the phenyl groups of $L$ and cyano ones from $\left[\mathrm{Ni}(\mathrm{CN})_{4}\right]^{2-}$ moieties (Fig. S7). Additionally and to probe the occurence of interlayers hydrogen bonds and $\pi-\pi$ a structure constituted by pair of layers with an aligned arrangement ligands was investigated also investigated by DFT (Fig. S6). The associated energy is comparable to that obtained previously for the 
aligned sequence. Nevertheless, owing to the experimental $L$ content greater than unity (i.e. 1.40 for $R-\mathbf{1}$ and $S-1$ ), some octahedral $\mathrm{Ni}^{2+}$ sites should incorporate two ligands involving that a mixed arrangement is most likely to occur.

\section{Adsorption Studies}

Sorption experiments were then performed to evaluate the efficiency of the chiral porous frameworks to induce an enantioselective adsorption. The TGA results already discussed indicate that the solids could be activated at $100{ }^{\circ} \mathrm{C}$ to avoid racemisation and under secondary vacuum without any loss other than water molecules. In order to confirm the integrity of the chiral coordination frameworks upon heating, both FT-IR and CD spectroscopies were carried out on the solid $R-1$ after such activation process. While the FT-IR spectrum (Fig. S8) is identical with respect to that of the pristine material, the CD clearly confirms that the chirality is retained upon the activation procedure (Fig. S9).

Firstly, the sorption features of the racemic adsorbent clathrate (+/-)-1 were studied using achiral $\mathrm{H}_{2} \mathrm{O}$ and racemic (+/-)butan-2-ol (referred as (+/-)-BuOH) probes. The water sorption isotherms (Fig. S10) exhibit a sigmoidal shape, indicating a switch from hydrophobic to hydrophilic character, as we previously evidenced in the case of related Prussian blue analogues. ${ }^{47}$ Namely, this step corresponds to a threshold related to the adsorption of water on the remaining CUS that in turn actuates the hydrophilic character of the framework. In contrast, this step appears for a largely greater relative pressure value when $(+/-)$ - $\mathrm{BuOH}$ vapour is used and shows a large hysteresis effect upon desorption. For both probes (water and (+/-)-BuOH), it could be noticed that the first step is located at a $Q_{\text {ads }}$ about 0.9 molecules which is close to the expected number of 1.06 CUS based on the previouly established formula. However, the water isotherm shows a continuous increase at high pressure to reach about 3 molecules due its adsorption into the residual porosity. This could be explained by the smaller size of water compared to $(+/-)$ - $\mathrm{BuOH}$. The observed water capacity for the racemic solid (+/-)-1 is comparable to that of the pristine clathrate $\mathbf{1}$ (i.e. $\left.2.5 \mathrm{H}_{2} \mathrm{O}\right)($ Fig. S11). For this later, it could be noticed that higher adsorpion capacities have been observed for instance in the $\mathrm{Mn}\left[\mathrm{Ni}(\mathrm{CN})_{4}\right]{ }^{48} \mathrm{Noticeably}$, the amount of water molecules in such systems remains a complex problem since it influences the crystal structure (three different phases are known). ${ }^{42-44}$ However it could be noticed that the non-functionalized material 1 shows a step at about a higher $1.8 \mathrm{H}_{2} \mathrm{O}$ per unit, in accordance with the two expected CUS in trans position of the octahedral $\mathrm{Ni}^{2+}$ ions. All these data clearly indicate that despite the PSM, the functionalized clathrates could efficiently adsorb different species in line with the obtained porous volumes based on nitrogen sorption isotherms (Fig. S12). Indeed, the hydrodynamic pore volumes of $\mathbf{1}, R-\mathbf{1}$ and (+/-)-1 were found to be $0.315 \mathrm{~cm}^{3} \cdot \mathrm{g}^{-1}, 0.198 \mathrm{~cm}^{3} \cdot \mathrm{g}^{-1}$ and $0.122 \mathrm{~cm}^{3} \cdot \mathrm{g}^{-1}$ respectively

To go further, the study of the adsorption of the same sorbates in the chiral functionalized material $R$-1 was performed (Fig. S13). Remarkably, it could be noticed that the steps of the water isotherms for $\mathbf{R}-\mathbf{1}$ and (+/-)-1 solids are located at an identical relative pressure pointing out a comparable hydrophobic/hydrophilic balance despite the slight difference in the $L$ content. The $Q_{\text {ads }}$ value corresponding to the step for the $R-\mathbf{1}$ adsorbent is found at 0.57 , in perfect accordance, with respect to the expected number of 0.60 CUS based on the chemical formula. Since the porous volume are close, this behavior could be at first glance explained by both, the larger amount of coordinated water in (+/-)-1 and the different structures of (+/-)-1 and $R-\mathbf{1}$.

To our knowledge, enantioselectivity towards an achiral probe has been only recently observed in the $\mathrm{MOF} \mathrm{Mg}_{2}(\mathrm{dobpdc})$ (dobpdc ${ }^{4-}=4,4^{\prime}$-dioxidobiphenyl-3,3'-dicarboxylate) functionalized by chiral diamines for $\mathrm{CO}_{2}$ adsorption. ${ }^{23} \mathrm{Yet} \mathrm{Mg}_{2}(\mathrm{dobpdc})$ crystallizes as racemate (containing equal amount of right and left-handed helices) and the subsequent functionalization induces the formation of diastereomeric domains that alter the non-covalent interactions with $\mathrm{CO}_{2}$. Such phenomenon could however not occur since the pristine clathrate 1 is not a racemate. Hence, the observed differences may be rather ascribed to different structural organizations of (+/-)-1 and $R-\mathbf{1}$ as evidenced by the XRD analysis. In addition, the (+/-)-BuOH isotherm with $R-\mathbf{1}$ exhibits a striking difference with respect to the racemic (+/-)-1 substrate (Fig. S13). Since (+/-)-BuOH is composed by an equimolar mixture of $R-$ $\mathrm{BuOH}$ and $\mathrm{S}-\mathrm{BuOH}$, such behaviour may reflect a chiral recognition effect induced by the formation of different diastereoisomeric domains.

Such scenario is further confirmed by studying the sorption isotherms of the racemic clathrate (+/-)-1 with either $R$-BuOH and $S-\mathrm{BuOH}$ chiral probes. To the best of our knowledge, such adsorption using chiral probes has never been performed in MOFs. The obtained sorption isotherms exhibit clear differences depending on the chirality of the sorbate (Fig. 4). Hence, using S-BuOH, the step in the isotherm is found at a lower relative pressure, while the saturation capacity is found $25 \%$ greater with those obtained with $R$ - $\mathrm{BuOH}$. It should be emphasized that enantioselectivity requires an interaction with an active site associated with a chirality. Although, the adsorption capacity (number of sorbates to be accomodated within the framework) could hardly be considered as a proof for enantioselectivity, the location of the step indirectly reflects the affinity of the sorbate for the solid. This suggests the occurrence of enantioselective recognition in our materials mostly caused by diastereoisomeric domains.

To study this phenomenon in details, the adsorption isotherms using both chiral probes $(R-\mathrm{BuOH}$ and $S$ - $\mathrm{BuOH})$ and the chiral material $R-1$ were performed. Firstly, one can notice in Fig. 5 that the adsorption capacities are found weaker with respect to those observed for racemic clatharate (+/-)-1. Such effect could be explained by the different chemical formulas of the clathrate that differs from the number of phenylehtylamine ligands. Hence, the weaker number of phenylethylamine (L) in (+/-)-1 explains its observed higher capacities with respect to the chiral clathrate. Secondly, Fig. 5 shows the $R$-BuOH sorption isotherms with $R$-1 and $S$-1 clathrates, pointing out the occurrence of distinct features, namely in both the location of the steps and the adsorption capacities. Such behaviour most likely arises from a diastereoisomeric effect obtained by the $R$ - $\mathrm{BuOH}$ adsorption generating either $R-1 @ R-B u O H$ and $S-1 @ R-B u O H$ pairs that shows different physico-chemical features. 


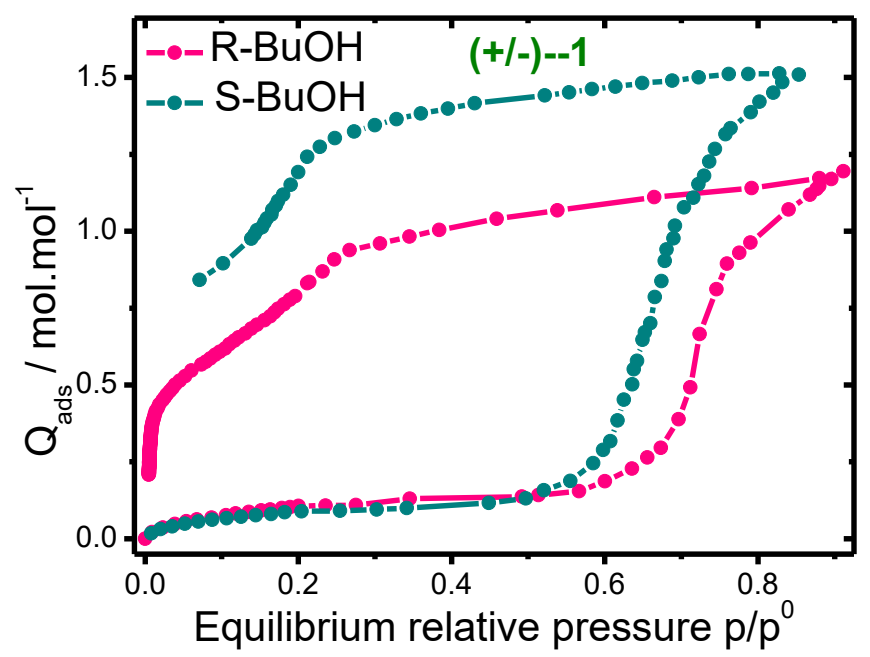

Fig. 4. Adsorption/desorption isotherms of $R-\mathrm{BuOH}$ and $S-\mathrm{BuOH}$ in the racemic (+/-)-1 clathrate.

To fully corroborate this, the different isotherms of enantiopure and racemic (+/-)-BuOH obtained with the chiral $R-\mathbf{1}$ clathrate as a substrate is shown in Fig. 6. One can observe an enantioselective effect depending on the BuOH chirality, in good accordance with the previous experiments. At first glance, the differences in the adsorption capacities may be viewed as less pronounced with respect to those obtained with the racemic clathrate (+/-)-1 (Fig. 4). However, it should be stressed that a quantitative comparison between $R-1$ and (+/-)-1 solids could not performed due to the difference in the phenylethylamine content in the materials. Interestingly, the sorption isotherms obtained with the racemic (+/-)-BuOH presents an intermediate behaviour: indeed, the step is located at a similar relative pressure value compared to the isotherm obtained with $R$-BuOH, but its saturation capacity is identical to $S-\mathrm{BuOH}$ adsorbate. Moreover, it could be noticed that the $R-\mathbf{1}$ clathrate seems to present a stronger affinity towards $\mathrm{S}-\mathrm{BuOH}$ based on both, the step location and adsorption capacity (Fig. 6). The conclusions drawn from the analysis of Fig. 5 and 6 point out: $i$ ) a specific interaction of the racemic (+/-)-BuOH towards the chiral clathrate $R-\mathbf{1}$ with respect to the racemic $(+/-)-\mathbf{1}$; ii) a difference in the interaction of $R-\mathrm{BuOH}$ and $S-\mathrm{BuOH}$ with $R-1$.

\section{Enantioselective separation}

Although, the energy difference in the enantioselective interaction between the enantiomers and the chiral clathrate is most likely very weak, this chiral recognition effect may be taken as an advantage to perform enantioselective separation in humid conditions, which still remains a challenge in the field of enantiomeric separation using molecule-based materials. To demonstrate this, the clathrate $\mathbf{R}-\mathbf{1}$ was used as a chiral stationary phase for performing high-performance liquid chromatography (HPLC) in a short home-made filled column. In light of the significant differences observed in the adsorption isotherms, we selected the same aliphatic alcohol (+/-)-BuOH for testing the enantioselective property of our material. Using a mobile acetonitrile/water (70\%/30\%) phase, the racemic (+/-)-BuOH could be separated by $R-\mathbf{1}$ into two clear adjacent peaks (Fig. 7) corresponding to the two constituting enantiomers as identified by the sign of the optical rotation obtained by polarimetry. Thus, $S$ - $\mathrm{BuOH}$ is eluted after $R$ $\mathrm{BuOH}$ indicating a preferential interaction of the former with $R-\mathbf{1}$, as suggested by the adsorption isotherms.

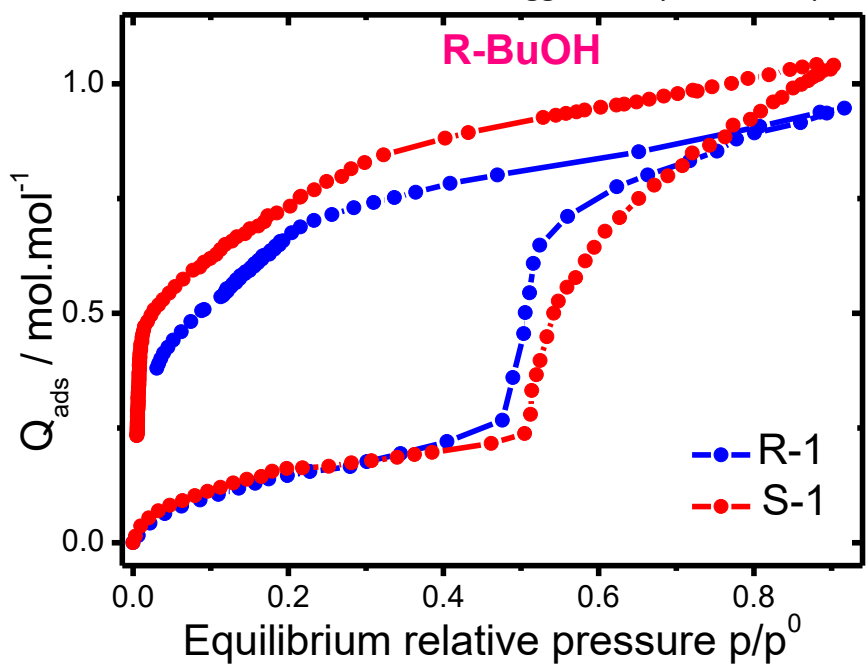

Fig. 5. $R$-BuOH adsorption isotherms for $R-1$ and $S-1$ solids. 
In our experimental conditions, it was not possible to achieve a better resolution, which might be consistent with the similarity of the adsorption enthalpies. Moreover, we have also performed the chromatographic separation with either pure $R$-BuOH or $S$ $\mathrm{BuOH}$ (Fig. S14). Although in our conditions, only a minor difference as regards the maximum of the peak could be observed, the $S$ - $\mathrm{BuOH}$ chromatogram shows a broader peak suggesting a preferential interaction with $R-\mathbf{1}$. It must be emphasized that the column was simply packed with particles of $R-\mathbf{1}$, which suggests that a better separation could be obtained by using a longer column with homogeneous particles of $R-\mathbf{1}$. Additionally, the injection of the racemic (+/-)-BuOH in a classical polar GC column (60 $\mathrm{m}$ long, $0.25 \mathrm{~mm}$ inner diameter) resulted in a single peak, emphasizing the performance of $R-1$ for the separation of enantiomers. To our knowledge, this is the first demonstration of such enantioselective separation in humid conditions in a molecule-based material, such as MOF or PCP.

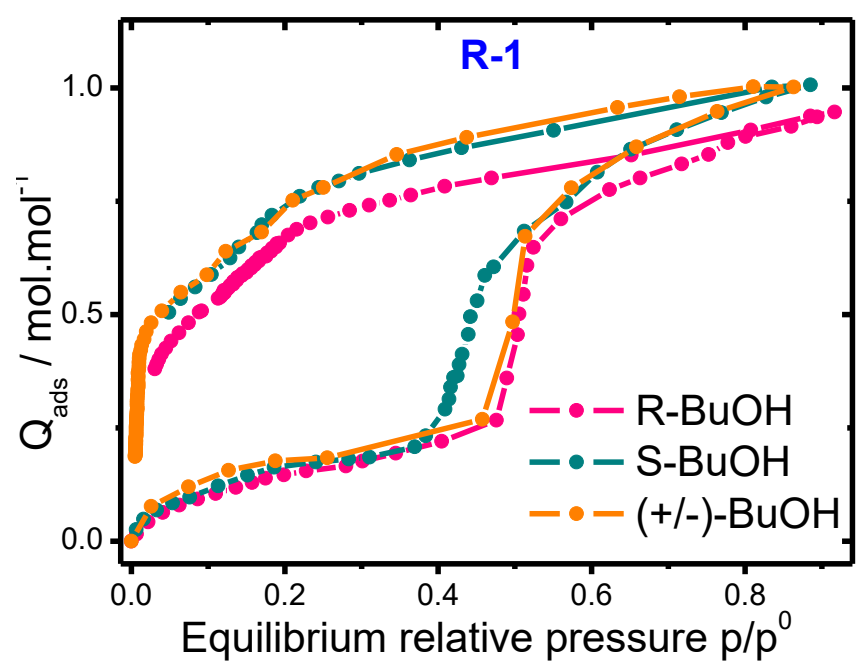

Fig. 6. Adsorption isotherms of $R-\mathrm{BuOH}, S-\mathrm{BuOH}$ and (+/-)- $\mathrm{BuOH}$ with the clathrate $R-1$.

\section{Molecular Simulations}

In order to give molecular insights on the enantioselective interaction, DFT calculations have been performed. Firstly, simple models constituted by pairs of either $R$ - $\mathrm{BuOH} / R$-phenylethylamine or $S$ - $\mathrm{BuOH} / R$-phenylethylamine were considered to validate the enantioselective effect. The plausible interactions are given in Fig. S15 and are mainly due to the accessibility of the butan-2ol to approach some parts of the $R$-phenylethylamine through hydrogen-bonds and $\mathrm{C}-\mathrm{H} / \pi$ interactions. It turns out that the difference in the interaction energy between one alcohol molecule and the ligand $R$-phenylethylamine at the molecular state is

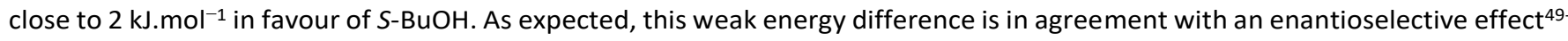
50 and is in line with the adsorption results.

To go further and explain the observed enantiomeric separation, Monte Carlo simulations were tested to probe the impact of coadsorption, knowing the plausible candidates for the clathrate structures with the parameters given in ESI and the partial charges for the two enantiomers of $\mathrm{BuOH}$ (Fig. S16). The adsorption enthalpy values calculated at low loading are slightly different $(\approx 1$ $\mathrm{kJ} . \mathrm{mol}^{-1}$ ) for $R$ - and $S$-BuOH in $R-1$ when mono-adsorption is investigated. Yet, the co-adsorption of the racemic mixture (+/-)$\mathrm{BuOH}$ with $R \mathbf{- 1}$ shows clearly an enantioselective effect.

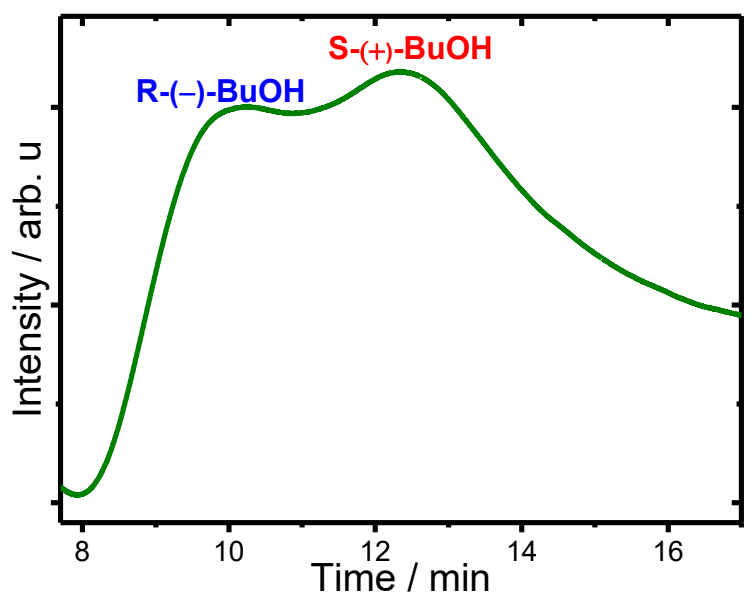

Fig. 7. Chromatogram of (+/-)-BuOH (acetonitrile:water 70:30) using the chiral $R$-1 clathrate. 


\begin{tabular}{|c|c|c|}
\hline \multirow{2}{*}{} & \multicolumn{2}{|c|}{ Adsorption Enthalpies (kJ.mol ${ }^{-1}$ ) } \\
\cline { 2 - 3 } & $\boldsymbol{R}$-1 (aligned) & \multicolumn{2}{|c|}{7 (alternated) } \\
\hline S-BuOH & 62.76 & 73.86 \\
\hline
\end{tabular}

Hence, difference in the distances of hydrogen-bonds and $\mathrm{C}-\mathrm{H} / \pi$ interactions between the alcohol molecules and both chemisorbed water molecules on the $\mathrm{Ni}^{2+}$ and phenyl rings of the framework (Fig. S17) are observed depending on the BuOH's chirality. As highlighted in the snapshots from the Fig. S16, the same type of interactions is observed between both, $R$ - and $S$-BuOH enantiomers with the $\mathbf{R} \mathbf{- 1}$ framework, but the different conformations of the alcohol molecules prevent from obtaining the same magnitude in their strength. This leads to a modification of the adsorption enthalpy values (Table 1), regardless the considered arrangement of the clathrate. Thus, a greater enthalpy adsorption is observed for $\mathrm{S}-\mathrm{BuOH}$. This suggests stronger interactions between $S-B u O H$ and $R-\mathbf{1}$, which is in perfect agreement with the chromatography separation results. Hence, this pronounced enantioselective effect when co-adsorption is envisaged highlights the critical role of the competition between $R$-BuOH and $S$ $\mathrm{BuOH}$ during the adsorption process.

\section{Conclusions}

In summary, we have described in this study the first example of post-functionalization to implement chirality in Hofmann clathrates. Hence, reaction of affordable enantiopure amines on the CUS of the two-dimensional clahtrate $\mathbf{1}$ allows the formation of chiral porous framework accessible at the multigram-scale. Studies of the adsorption isotherms indicate a clear enantioselectivity, which makes these compounds excellent candidates for the chiral separation. Indeed and owing to their great hydrostability, the chiral clathrates are able to separate a racemic mixture of butan-2-ol in humid conditions. Molecular simulations provided microscopic insights into the structural properties and the enantioselective interaction between the chiral clathrates and the butan-2-ol helping to understand this enantioselective preference. This approach could be easily extended to various coordination frameworks of different nature and opens tremendous potentialities for the chiral separation of hydrosoluble compounds.

\section{Experimental}

\section{Materials and Methods}

All chemical reagents were purchased and used without further purification: Nickel(II) nitrate hexahydrate (Alfa Aesar, 98\%), Potassium tetracyanonickelate (II) (Aldrich, 99.9\%), R-(+)-1-Phenylethylamine (Alfa Aesar, 98\%), S-(-)-1-Phenylethylamine (Alfa Aesar, 98\%), (+/-)-1-Phenylethylamine (ABCR, 98\%), ultra-pure water, Chloroform pure stabilized with ethanol (Carlo Erba).

\section{Synthesis of $\left[\mathrm{Ni}\left(\mathrm{H}_{2} \mathrm{O}\right)_{2}\right]\left[\mathrm{Ni}(\mathrm{CN})_{4}\right] \bullet 1.5 \mathrm{H}_{2} \mathrm{O}(1)$}

The compound was obtained by modified procedure. ${ }^{39}$ At $25{ }^{\circ} \mathrm{C}$, aqueous solution of $\mathrm{K}_{2}\left[\mathrm{Ni}(\mathrm{CN})_{4}\right](0.8 \mathrm{M}, 50 \mathrm{~mL})$ was added dropwise to an aqueous solution of $\mathrm{Ni}\left(\mathrm{NO}_{3}\right)_{2} \cdot 6 \mathrm{H}_{2} \mathrm{O}(0.8 \mathrm{M}, 50 \mathrm{~mL})$. A blue precipitate is formed immediately. After addition, the reaction mixture was refluxed for 1 hour. The precipitate was removing by filtration, washed with ultrapure water several times and dried in the air at $60^{\circ} \mathrm{C}$. Light blue powder. IR $\left(\mathrm{KBr}, \mathrm{cm}^{-1}\right): 2171$ (s) v(Ni"l-CN-Ni"), 2132 (sh). EDS: 0.72/99.28 (K/Ni). Elemental analysis calcd (\%): C, 16.59; H, 2.46; N, 19.69; found (\%): C, 16.49; H, 2.09; N, 19.83 .

\section{Synthesis of $\left[\mathrm{Ni}\left(R-(+)-\mathrm{C}_{8} \mathrm{H}_{11} \mathrm{~N}\right)_{1.40}\left(\mathrm{H}_{2} \mathrm{O}\right)_{0.60}\right]\left[\mathrm{Ni}(\mathrm{CN})_{4}\right] \bullet 0.3 \mathrm{H}_{2} \mathrm{O}(R-1)$.}

The solid 1 ( $9 \mathrm{mmol}, 3.0 \mathrm{~g}$ ) was activated at $130^{\circ} \mathrm{C}$ under vacuum for 2 hours. Then, it was cooled to room temperature under argon. The solution of $R-(+)-1$-Phenylethylamine in chloroform $(0.1 \mathrm{M}, 180 \mathrm{~mL})$ was added under argon to the activated orange solid. The reaction mixture became gray and was stirred under argon overnight. Then, the precipitate was recovered by filtration, washed with chloroform and dried in the air at $60^{\circ} \mathrm{C}$. Lavender solid. IR $\left(\mathrm{KBr}, \mathrm{cm}^{-1}\right): 2167 \mathrm{v}\left(\mathrm{Ni}{ }^{\prime \prime}-\mathrm{CN}-\mathrm{Ni}\right.$ "); 2125 . EDS: $0.49 / 99.51$ $(\mathrm{K} / \mathrm{Ni})$. Elemental analysis calcd (\%): $\mathrm{C}, 44.76 ; \mathrm{H}, 4.22 ; \mathrm{N}, 18.55$; found (\%): $\mathrm{C}, 44.60 ; \mathrm{H}, 4.09 ; \mathrm{N}, 18.75$. Estimated formula for $R-1$ : $\left[\mathrm{Ni}\left(R-(+)-\mathrm{C}_{8} \mathrm{H}_{11} \mathrm{~N}\right)_{1.4}\left(\mathrm{H}_{2} \mathrm{O}\right)_{0.60}\right]\left[\mathrm{Ni}(\mathrm{CN})_{4}\right] \cdot 0.3 \mathrm{H}_{2} \mathrm{O}$

\section{Synthesis of $\left[\mathrm{Ni}\left(\mathrm{S}-(-)-\mathrm{C}_{8} \mathrm{H}_{11} \mathrm{~N}\right)_{1.40}(\mathrm{H} 2 \mathrm{O})_{0.60}\right]\left[\mathrm{Ni}(\mathrm{CN})_{4}\right] \bullet 0.3 \mathrm{H}_{2} \mathrm{O}(\mathrm{S}-1)$}

Following the same procedure for $R-\mathbf{1}$, compound $S-\mathbf{1}$ was prepared by addition of the solution of S-(-)-1-Phenylethylamine in chloroform $(0.1 \mathrm{M}, 180 \mathrm{~mL})$ to the activated solid $1(9 \mathrm{mmol}, 3.0 \mathrm{~g})$ under argon. The reaction mixture became gray and was stirred under argon overnight. Then, the precipitate was recovered by filtration, washed with chloroform and dried in the air at $60^{\circ} \mathrm{C}$. Lavender solid. IR $\left(\mathrm{KBr}, \mathrm{cm}^{-1}\right): 2166, \mathrm{v}\left(\mathrm{Ni}^{\prime \prime}-\mathrm{CN}-\mathrm{Ni}^{\prime \prime}\right)$, 2125. EDS: 0.70/99.30 (K/Ni). Elemental analysis calcd (\%): $\mathrm{C}, 44.73 ; \mathrm{H}, 4.22 ; \mathrm{N}$, 18.55; found (\%): C, 43.91; $\mathrm{H}, 3.64 ; \mathrm{N}, 18.42$. Estimated formula for $\mathrm{S}-1$ : $\left[\mathrm{Ni}\left(\mathrm{S}-(-)-\mathrm{C}_{8} \mathrm{H}_{11} \mathrm{~N}\right)_{1.4}\left(\mathrm{H}_{2} \mathrm{O}\right)_{0.60}\right]\left[\mathrm{Ni}(\mathrm{CN})_{4}\right] \bullet 0.3 \mathrm{H}_{2} \mathrm{O}$ 


\section{Synthesis of $\left[\mathrm{Ni}\left((+/-)-\mathrm{C}_{8} \mathrm{H}_{11} \mathrm{~N}\right)_{0.94}\left(\mathrm{H}_{2} \mathrm{O}\right)_{1.06}\right]\left[\mathrm{Ni}(\mathrm{CN})_{4}\right] \bullet 1.2 \mathrm{H}_{2} \mathrm{O}((+/-)-1)$}

Following the same procedure for $R-\mathbf{1}$, the racemic compound (+/-)-1 was prepared by addition of the solution of racemic (+/-)1-Phenylethylamine in chloroform $(0.1 \mathrm{M}, 180 \mathrm{~mL})$ to the solid $1(9 \mathrm{mmol}, 3.0 \mathrm{~g})$ under argon. The reaction mixture became grey and was stirred under argon overnight. Then, the precipitate was recovered by filtration, washed with chloroform and dried in the air at $60^{\circ} \mathrm{C}$. Light blue solid. IR $\left(\mathrm{KBr}, \mathrm{cm}^{-1}\right)$ : 2166, $\mathrm{v}\left(\mathrm{Ni}^{\prime \prime}-\mathrm{CN}-\mathrm{Ni}{ }^{\prime \prime}\right) ; 2125$. EDS: 0.36/99.64 (K/Ni). Elemental analysis calcd (\%): C, 36.40; $\mathrm{H}, \quad 3.93 ; \mathrm{N}, 18.21$; found $(\%)$ : C, 35.24; $\mathrm{H}, 4.09 ; \mathrm{N}, 17.65$. Estimated formula for (+/-)-1: $[\mathrm{Ni}((+/-)-$ $\left.\left.\mathrm{C}_{8} \mathrm{H}_{11} \mathrm{~N}\right)_{0.94}\left(\mathrm{H}_{2} \mathrm{O}\right)_{1.06}\right]\left[\mathrm{Ni}(\mathrm{CN})_{4}\right] \bullet 1.2 \mathrm{H}_{2} \mathrm{O}$

\section{Infrared Spectroscopy}

Infrared spectra were recorded as KBr disks on a PerkinElmer Spectrum two spectrophotometer.

\section{X-ray Powder Diffraction}

$\mathrm{X}$-ray powder diffraction patterns were recorded in the $2 \theta$ interval $4-60^{\circ}$ at room temperature with a PANalytical X'Pert PRO MPD $\theta-\theta$ diffractometer in Bragg-Bentano geometry, with the $\mathrm{Cu}-\mathrm{K} \alpha$ radiation $(\lambda=1.5418 \AA$ ). From each powder diffraction pattern, the unit cell was determined using the Treor and Dicvol programs. Then the cell parameters were refined by the Le Bail method with the Fullprof program using the WinPLOTR interface.

\section{Scanning Electronic Microscopy}

Scanning Electronic Microscopy (EDS) analyses were performed on a FEI Quanta FEG 200 instrument. The powders were deposited on an adhesive carbon film and analysed under vacuum. The quantification of the heavy elements was carried out with the INCA software, with a dwell time of $3 \mu \mathrm{s}$.

\section{Thermogravimetric Analysis}

Thermogravimetric analyses were obtained with a thermal analyser STA 409 Luxx ${ }^{\circledR}$ (Netzsch) in the range $25-600{ }^{\circ} \mathrm{C}$ at heating speed of $5^{\circ} \mathrm{C} / \mathrm{min}$.

\section{Circular Dicrhoism}

CD measurements were performed on a Jasco J-815 Circular Dichroism Spectropolarimeter at $298 \mathrm{~K}$ in solid state (KBr pellets). To prepare pellet for measurements, $1 \mathrm{mg}$ of sample was mixed with $100 \mathrm{mg}$ of $\mathrm{KBr}$. A scan speed of $100 \mathrm{~nm}$. min ${ }^{-1}$ with data interval of $0.1 \mathrm{~nm}$ and bandwidth of $10 \mathrm{~nm}$ was used.

\section{Polarimetry}

The optical activity measurement was performed on a Polarimeter PerkinElmer Model 341 with Na source lamp with spectral line at $589 \mathrm{~nm}$ and Glan-Taylor polarizer.

\section{Adsorption Isotherms}

The vapor adsorption/desorption experiments have been performed with a home-made apparatus already described elsewhere. ${ }^{51}$ This set-up is based on manometric measurements (with two capacitive pressure gauges (0-10 Torr and 0-1000 Torr). The sample cell can be disconnected from the system to undergo a thermal treatment up to $250^{\circ} \mathrm{C}$ (depending on the thermal stability of the sample) under a vacuum of $10^{-3}$ Torr. The adsorption set-up presented above allows for the choice of the pressure of the adsorbate to be introduced (instead of the equilibrium pressure). The adsorbed amounts $\left(Q_{a d s}\right)$ were determined as the difference between equilibrium pressure before adsorption and after adsorption for each adsorption step.

\section{Liquid Chromatography}

The HPLC column of $5 \mathrm{~cm}$ long, and $4 \mathrm{~mm}$ inner diameter was packed with $R$-1. Such column was used in High-performance liquid chromatograph Shimadzu equipped with a variable-wavelength ultraviolet detector as well as with a refractive index detector. 2 $\mu \mathrm{L}$ of different butanol solutions $\left(0.08 \mu \mathrm{g} \cdot \mathrm{mL}^{-1}\right)$ were injected onto column. The mobile phase (water:acetonitrile $\left.30: 70\right)$ was set at a flow rate of $0.1 \mathrm{~mL} \cdot \mathrm{min}^{-1}$. Column temperature was $40^{\circ} \mathrm{C}$. Two fractions of the eluted mixture were collected in two vials for further optical identification. The first fraction was taken between 8 and $11 \mathrm{~min}$ of retention time, the second fraction was taken between 11 and $14 \mathrm{~min}$ of retention time (Fig. 7). As the two chromatographic peaks are not baseline resolved, it can be anticipated that the first fraction contains principally the first eluted enantiomer $(R-\mathrm{BuOH})$ and traces of the second enantiomer $(S-\mathrm{BuOH})$. The opposite situation applies for the second fraction which should mostly contain the $S$-BuOH enantiomer to come out.

\section{Computational Section}

In order to provide microscopic insights of the interactions of the solids with the adsorbed molecules as well as to determine plausible crystal structures, DFT calculations have been performed. First, DFT calculations have probed the impact of the chirality 
of the butan-2-ol $(\mathrm{BuOH})$ molecules and the phenylethylamine ligand. For that purpose, geometry optimizations on many molecular models were determined with $\mathrm{DMol}^{3}$ and PW91 GGA density functional and the double numerical basis set containing polarization (DNP) functions were used with high levels of convergence. The results of these simulations are discussed regarding the chirality of the adsorbed molecules (Fig. S14). In order to simplify the system, only the ligand issued from the solid structure has been considered.

Second, a plausible crystal structure has been determined using periodic DFT calculations for $R$ - and $S$ - conformation of the ligand. A computational-assisted structure determination has been followed by combining structure determination using XRD refinements and computational geometry optimizations.

Again, PW91 GGA density functional and the double numerical basis set containing polarization (DNP) functions were used with high levels of convergence in order to determine the range of unit cell parameters and then to determine the plausible crystal structures. The initial step consists into building the starting configurations in $P 1$ symmetry by bonding the phenylethylamine ligands on the octahedral $\mathrm{Ni}^{2+}$ centers with a ratio $1: 1$ with $R$ - or $S$ - conformations. Then geometry optimizations were performed using DFT calculations with free cell parameters. Keep in mind that the co-obtained crystal structures should be dependent from the initial distribution of the ligands. Therefore the simulated unit cell parameters were injected in order to help the refinement of experimental data using Fullprof, as described in the X-ray powder diffraction part. Finally, the last geometry optimization of the unit cell was performed by imposing the experimental parameters. To go further, different organizations of the chiral ligands have been tested in the DFT calculations in order to probe the impact of this organization on the structure energy. The different organizations tested have been summarized in the Fig. 1 and Fig. S6, while the main interactions determined in the structures are reported in the Fig. $\mathrm{S} 7$ for the $R$ - and $S$ - conformations as well as for the different distributions of the ligands in the interlayer spaces.

Endly, knowing the crystal structures for the two chiral clathrates, it is therefore possible to estimate the adsorption enthalpy values for $R$ - and $S$-BuOH and for racemic mixture. For that purpose, Monte Carlo simulations in the NVT ensemble were performed using a home-made code to probe the interactions between the framework of the solid and an enantiopure molecule of alcohol or a racemic mixture (1 for each enantiomer). In this case, it is necessary to calculate both the Van der Waals and the electrostatic interactions. The Van der Waals interactions are determined from the Lennard Jones parameters issued from UFF, ${ }^{52}$ with a cut-off for the long interactions fixed at $12.5 \AA$ A. Using DFT calculations and the resulting ESP partial charges for the $R$ - and $S$-butanol molecules (Fig. S15) combined with classical partial charges (issued from the Electronegativity Equalization Method) for the solid framework atoms, it is possible to evaluate the electrostatic interactions using the Ewald summation. For these calculations, a rigid multi-cell structure $(4 \times 2 \times 2)$ was considered and 10 millions of steps were used for both equilibration and production and calculations were performed at $300 \mathrm{~K}$.

\section{Acknowledgements}

The authors thank the University of Montpellier, CNRS and PAC of ICGM.

\section{Notes and references}

1 L. Pasteur, Annales Chimie Phys., 1848, 24, 442-459.

2 T. Ito, H. Ando, T. Suzuki, T. Ogura, K. Hotta, Y. Imamura, Y. Yamaguchi and H. Handa, Science, 2010, 327, 1345.

3 R. Natarajan, S. C. Basak, A. T. Balaban, J. A. Klun and W. F. Schmidt, Pest Management Science, 2005, 61, 1193-1201.

4 L. Ma, C. Abney and W. Lin, Chem. Soc. Rev., 2009, 38, 1248-1256.

5 K. W. Plaxco and M. Gross, Astrobiology: a brief introduction, JHU Press, 2011.

6 R. Bentley, in Reviews in Cell Biology and Molecular Medicine, DOI: 10.1002/3527600906.mcb.200200008.

7 R. E. Morris and X. Bu, Nat. Chem., 2010, 2, 353.

8 H.-S. Wang and J.-P. Wei, Nanoscale, 2015, 7, 11815-11832.

9 L. A. Nguyen, H. He and C. Pham-Huy, Int. J. Biomed. Sci., 2006, 2, 85-100.

10 M. Xue, B. Li, S. Qiu and B. Chen, Mater. Today, 2016, 19, 503-515.

11 J. Corbin and L. B. Rogers, Anal. Chem., 1970, 42, 1786-1789.

12 Y. Okamoto and T. Ikai, Chem. Soc. Rev., 2008, 37, 2593-2608.

13 M. Lämmerhofer, J. Chromatogr. A, 2010, 1217, 814-856.

14 B. Chankvetadze, J. Chromatogr. A, 2012, 1269, 26-51.

15 E. Yashima, K. Maeda, H. lida, Y. Furusho and K. Nagai, Chem. Rev., 2009, 109, 6102-6211.

16 J. Zhang, S. Chen and X. Bu, Angew. Chem. Int. Edit., 2009, 48, 6049-6051.

17 T. Duerinck and J. F. M. Denayer, Chem. Eng. Sci., 2015, 124, 179-187.

18 Z. Y. Gu and X. P. Yan, Angew. Chem. Int. Edit., 2010, 49, 1477-1480.

19 X. Zhao, Y. Wang, D.-S. Li, X. Bu and P. Feng, Adv. Mater., 2018, 30, 1705189.

20 Q. Zhang, Y. Cui and G. Qian, Coord. Chem. Rev., 2019, 378, 310-332.

21 L. Pérez-García and D. B. Amabilino, Chem. Soc. Rev., 2002, 31, 342-356. 
22 S. Lee, E. A. Kapustin and O. M. Yaghi, Science, 2016, 353, 808-811.

23 J. D. Martell, L. B. Porter-Zasada, A. C. Forse, R. L. Siegelman, M. I. Gonzalez, J. Oktawiec, T. Runčevski, J. Xu, M. Srebro-Hooper, P. J. Milner, K. A. Colwell, J. Autschbach, J. A. Reimer and J. R. Long, J. Am. Chem. Soc., 2017, 139, 16000-16012.

24 S.-Y. Zhang, D. Li, D. Guo, H. Zhang, W. Shi, P. Cheng, L. Wojtas and M. J. Zaworotko, J. Am. Chem. Soc., 2015, 137, $15406-15409$.

25 J. S. Seo, D. Whang, H. Lee, S. I. Jun, J. Oh, Y. J. Jeon and K. Kim, Nature, 2000, 404, 982.

26 L. Ma, J. M. Falkowski, C. Abney and W. Lin, Nat. Chem., 2010, 2, 838.

27 K. K. Tanabe and S. M. Cohen, Chem. Soc. Rev., 2011, 40, 498-519.

28 M. Banerjee, S. Das, M. Yoon, H. J. Choi, M. H. Hyun, S. M. Park, G. Seo and K. Kim, J. Am. Chem. Soc., 2009, 131, 7524-7525.

29 J. Canivet, A. Fateeva, Y. Guo, B. Coasne and D. Farrusseng, Chem. Soc. Rev., 2014, 43, 5594-5617.

30 J. Duan, W. Jin and S. Kitagawa, Coord. Chem. Rev., 2017, 332, 48-74.

31 J. Liu, F. Wang, Q.-R. Ding and J. Zhang, Inorg. Chem., 2016, 55, 12520-12522.

32 Q. Zhang, M. Lei, F. Kong and Y. Yang, Chem. Commun., 2018, 54, 10901-10904.

33 L. Boudjema, E. Mamontova, J. Long, J. Larionova, Y. Guari and P. Trens, Inorg. Chem., 2017, 56, 7598-7601.

34 K. Otsubo, T. Haraguchi and H. Kitagawa, Coord. Chem. Rev., 2017, 346, 123-138.

35 Z.-P. Ni, J.-L. Liu, M. N. Hoque, W. Liu, J.-Y. Li, Y.-C. Chen and M.-L. Tong, Coord. Chem. Rev., 2017, 335, $28-43$.

36 R. Ohtani and S. Hayami, Chem. Eur. J., 2017, 23, 2236-2248.

37 K. A. Zenere, S. G. Duyker, E. Trzop, E. Collet, B. Chan, P. W. Doheny, C. J. Kepert and S. M. Neville, Chem. Sci., 2018, 9, 5623-5629.

38 C. Bartual-Murgui, N. A. Ortega-Villar, H. J. Shepherd, M. C. Muñoz, L. Salmon, G. Molnár, A. Bousseksou and J. A. Real, J. Mater. Chem., 2011, 21, 7217-7222.

39 J. T. Culp, S. Natesakhawat, M. R. Smith, E. Bittner, C. Matranga and B. Bockrath, J. Phys. Chem. C, 2008, 112, 7079-7083.

40 J. T. Culp, M. R. Smith, E. Bittner and B. Bockrath, J. Am. Chem. Soc., 2008, 130, 12427-12434.

41 J. T. Culp, C. Madden, K. Kauffman, F. Shi and C. Matranga, Inorg. Chem., 2013, 52, 4205-4216.

42 O. Reyes-Martinez, E. Torres-García, G. Rodríguez-Gattorno and E. Reguera, Materials, 2013, 6.

43 W. K. Ham, T. J. R. Weakley and C. J. Page, J. Solid State Chem., 1993, 107, 101-107.

44 Q. Li, X. Sha, S. Li, K. Wang, Z. Quan, Y. Meng and B. Zou, J. Phys. Chem. Lett., 2017, 8, 2745-2750.

45 G. Massasso, J. Long, C. Guerin, A. Grandjean, B. Onida, Y. Guari, J. Larionova, G. Maurin and S. Devautour-Vinot, J. Phys. Chem. C, 2015, 119, 9395-9401.

46 Y. Mathey and C. Mazieres, Can. J. Chem., 1974, 52, 3637-3644.

47 L. Boudjema, J. Long, F. Salles, J. Larionova, Y. Guari and P. Trens, Chem. - Eur. J., 2019, 25, 479-484.

48 A. Alowasheeir, S. Tominaka, Y. Ide, Y. Yamauchi and Y. Matsushita, Cryst. Eng. Comm., 2018, 20, 6713-6720.

49 R. Hailili, L. Wang, J. Qv, R. Yao, X.-M. Zhang and H. Liu, Inorg. Chem., 2015, 54, 3713-3715.

50 J. Navarro-Sánchez, A. I. Argente-García, Y. Moliner-Martínez, D. Roca-Sanjuán, D. Antypov, P. Campíns-Falcó, M. J. Rosseinsky and C. Martí-Gastaldo, J. Am. Chem. Soc., 2017, 139, 4294-4297.

51 P. Trens, N. Tanchoux, A. Galarneau, D. Brunel, B. Fubini, E. Garrone, F. Fajula and F. Di Renzo, Langmuir, 2005, 21, 8560-8564.

52 A. K. Rappe, C. J. Casewit, K. S. Colwell, W. A. Goddard and W. M. Skiff, J. Am. Chem. Soc., 1992, 114, 10024-10035. 